\title{
Non-Rural Point Source Blastomycosis Outbreak Near a Yard Waste Collection Site
}

John R. Pfister, MS; John R. Archer, MS; Shelly Hersil, BS, CHES; Tammi Boers, RS; Kurt D. Reed, MD, MGIS; Jennifer K. Meece, PhD; Jennifer L. Anderson, BS; Joshua W. Burgess, PhD; Thomas D. Sullivan, PhD; Bruce S. Klein, MD; L. Joseph Wheat, MD; and Jeffrey P. Davis, MD

Background: Blastomycosis is a potentially fatal infection caused by the fungus Blastomyces dermatitidis. During January I through March 5, 2006, twenty-one laboratory confirmed cases of blastomycosis were reported among residents of an endemic area in north-central Wisconsin; a striking increase compared with previous years. The objective of the study was to determine if an observed increase in blastomycosis among residents of an urban area in north-central Wisconsin was caused by a pointsource exposure and to identify its source.

Methods: We compared epidemiologic features, and signs and symptoms of $B$. dermatitidis infection among 46 historic (1999-2005) and 21 possible outbreak case patients. In addition, a case-control study was conducted to compare risk factors of the outbreak case patients with those of 64 age, gender, and geographically-matched control subjects. We conducted site inspections, evaluated meteorological data, genetically compared outbreak and non-outbreak isolates, and attempted environmental detection of $B$. dermatitidis using polymerase chain reaction, in vitro isolation, and in vivo isolation by tail vein injection of mice.

Results: The unusual risk profile of this outbreak included: residence within non-rural city limits with limited time spent outdoors and an equivalent gender ratio and young median age among case patients consistent with common source rather than unrelated exposures. Thirteen of fourteen outbreakassociated clinical isolates of $B$. dermatitidis clustered in the same genetic group by PCR-RFLP analysis. Inspections near the cluster center suggested a yard waste collection site as the probable exposure source. B. dermatitidis nucleic acid was detected in one of 19 environmental samples. Environmental and meteorological conditions and material management practices were identified that may have facilitated growth and dispersal of B. dermatitidis conidia near this residential area.

Conclusions: Results of our investigation of this large non-rural outbreak of blastomycosis suggest bioaerosol hazards may exist near yard waste collection and composting facilities, especially where pine tree litter is present, in B. dermatitidis endemic areas.

Keywords: Bioaerosol; Blastomyces dermatitidis; Blastomycosis; Outbreak

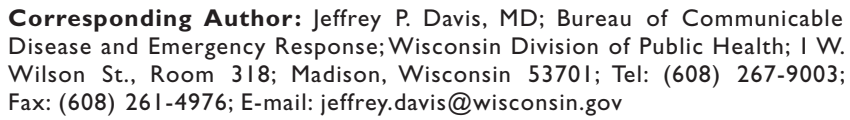

Corresponding Author: Jeffrey P. Davis, MD; Bureau of Communicable Disease and Emergency Response; Wisconsin Division of Public Health; I W. Wilson St., Room 318; Madison, Wisconsin 53701; Tel: (608) 267-9003; Fax: (608) 26I-4976; E-mail: jeffrey.davis@wisconsin.gov

Received: July 23, 2010

Revised: September 22, 2010

Accepted: September 23, 2010

doi: $10.3121 / \mathrm{cmr} .2010 .958$

Disclosures: Laboratory testing was provided by the University of Wisconsin-Madison School of Medicine and Public Health, the Marshfield Clinic Research Foundation, and MiraVista Diagnostics. L.J.W. is owner of MiraVista Diagnostics and MiraBella Technologies, companies that provide commercial testing services for diagnosis of blastomycosis by antigen detection. No other authors report potential conflicts. 
B lastomycosis is a chronic granulomatous mycosis caused by the dimorphic fungus Blastomyces dermatitidis. ${ }^{1}$ The organism exists as a mold at ambient temperature in the environment but transforms into a pathogenic yeast after infectious spores are inhaled by susceptible mammalian hosts. In the United States, most cases occur in the Ohio and Mississippi river valleys, the southeastern states, and around the Great Lakes. Clinical presentation most often mimics a viral or bacterial respiratory infection. However, specific diagnosis is often complicated by the fact that the spectrum of illness is so variable, ranging from asymptomatic or minimally symptomatic self-limited pulmonary disease to rapidly progressive fatal illness with fulminant pneumonia and dissemination to skin, bone, the central nervous system, and other organ systems. ${ }^{2}$

Epidemiologic investigation of blastomycosis is impeded by lack of reliable skin or serologic tests to ascertain infection and extreme difficulty in isolating $B$. dermatitidis from the environment. ${ }^{3}$ In vitro and environmental studies suggest $B$. dermatitidis grows in geographically-restricted microfoci associated with waterways in acidic soils and decaying organic material. Moisture facilitates liberation of conidia which may then be dispersed by air currents. ${ }^{4}$ Recent investigations of the ecological niche(s) of $B$. dermatitidis in Wisconsin demonstrate a strong association with waterways in urban and rural environments in northern, northeastern, and southeastern regions of the state. ${ }^{5,6}$

Most cases of blastomycosis are sporadic. Infrequently, clusters of cases are reported during extended intervals in endemic areas or related to presumed common source exposures. These outbreaks generally involve small numbers of cases, and all but one has historically occurred in rural settings. During the first six weeks of 2006, an apparent increase of laboratory-confirmed cases of blastomycosis occurred among residents of a small community in the 54452 zip code tabulation area (ZCTA) in north-central Wisconsin, prompting epidemiologic, environmental, and laboratory investigations. We describe the largest reported non-rural outbreak of blastomycosis and identify the probable mechanism of point source exposure.

\section{Methods}

Epidemiologic Investigations

Case definition: A confirmed outbreak case of blastomycosis was defined as (1) an illness clinically consistent with pulmonary or extrapulmonary blastomycosis; (2) with illness onset from January 1 through March 5, 2006; (3) in a resident of the 54452 ZCTA in north-central Wisconsin; and (4) isolation of $B$. dermatitidis or visualization of characteristic broad-based budding yeasts from an appropriate clinical specimen.

Historical Case Comparison: A standard blastomycosis case report form developed by the Wisconsin Division of Public
Health (WDPH) in 2003 was used to obtain demographic, clinical, diagnostic, risk factor, and exposure history data (a less detailed form was used prior to 2003). Clinical and demographic features among outbreak (case definition as described above) and historic case patients (onsets during 1999 through 2005, $\mathrm{n}=46$ ) were assessed for differences in epidemiologic features, and signs and symptoms using the chi-square test with Yates correction, two-tailed Fisher exact test, or the Kruskal-Wallis test.

Case-Control Study: A case-control study was conducted to compare risk factors of the outbreak case patients with those of control subjects $(n=64)$ recruited from the same ZCTA using random digit dialing procedures. ${ }^{7}$ Recruitment of three control subjects per case patient, matched by gender and age group, was attempted for each case patient using the following scheme: within 2 years for case patients $<10$ years of age; within 5 years for case patients between 10 and 24 years of age; and within 10 years for case patients $\geq 25$ years of age. We also recruited city employees that worked in close proximity to the possible exposure site, household members of case patients, and workers or clients from a daycare facility located near the possible exposure site. Data were analyzed for associations between the presence of disease and characteristics and activities during the estimated exposure periods thought to be relevant to the acquisition of $B$. dermatitidis infection. Maximum likelihood estimates (MLE) of the matched odds ratios (mOR) using the Mantel-Haenszel procedure, with exact $95 \%$ mid-point confidence intervals and $P$ values, were calculated using EpiInfo. ${ }^{9}$

\section{Environmental Investigations}

Point Source Investigation: Exposure periods (and median exposure dates), defined as 3 to 12 weeks (45 days) prior to the onset of symptoms, were estimated for each of the outbreak case patients. ${ }^{8}$ The geographic median center of the outbreak cluster was located using CrimeStat software. ${ }^{10}$ Meteorological data from January 1, 2005 through February 12, 2006 were reviewed to determine specific weather conditions that may have contributed to the outbreak. ${ }^{11}$ Interviews and inspections were conducted by local and state health department personnel to identify likely exposure sites.

Environmental (soil) samples were collected from multiple compost piles located in a municipal yard waste collection site where the exposures were believed to have occurred. In addition, samples were collected from a pile of pine tree litter that was relocated to an off-site facility, via an open-bed truck, just prior to sampling, but was present at the municipal site at the estimated time of exposure. A total of 19 environmental samples were collected.

\section{Laboratory Investigations}

Environmental samples: Attempts to detect B. dermatitidis in environmental samples were made using polymerase chain reaction (PCR) with Blasto I and Blasto II primers, ${ }^{12,13}$ in vitro isolation, ${ }^{14}$ and in vivo isolation by tail vein injection of 
mice. $^{15}$ All animal protocols were approved by the Marshfield Clinic Research Foundation Institutional Animal Care and Use Committee before commencement of mouse inoculation.

Outbreak Isolate Typing: Clinical $B$. dermatitidis isolates from epidemiologically linked outbreak case patients were compared for genetic similarities with ATCC strain \#26199 and 40 isolates obtained between 2005 and 2007 from human, feline, canine, and equine sources across Wisconsin, including non-outbreak cases from the same 54452 ZCTA. Polymerase chain reaction-restriction fragment length polymorphism analysis (PCR-RFLP) was conducted as previously described. ${ }^{16}$ DNA band patterns were analyzed with BioNumerics software (BioSystematica, Wales, UK) and strains were matched for percentage similarities by the Dice method with a $1.5 \%$ interband tolerance. Dendrograms were generated by the unweighted pair-group method with arithmetic mean. ${ }^{17}$

Serology and Antigen Detection: Urine and serum specimens were provided by nine case patients, thirty-six control subjects (recruited from the case-control study), three household members of case patients, six city employees, and six employees or clients of a child daycare facility in close proximity to the case cluster area. Testing was conducted as previously described using an enzyme immunoassay (EIA) to detect $B$. dermatitidis antigenuria, ${ }^{18}$ and modification of a serologic EIA for antibody to recombinant $B$. dermatitidis BAD1 antigen. ${ }^{19}$

\section{Results}

Clinical and Epidemiologic Findings

Clinical Cases: Twenty-one patients had laboratory confirmed outbreak cases of blastomycosis. Among the 21 outbreak cases, 20 were culture-confirmed Blastomyces dermatitidis infections and the diagnosis on the remaining (fatal) case was based on a $\mathrm{KOH}$ stain of sputum. Eighteen of the twenty-one outbreak case-patients had pulmonary involvement only; two patients had disseminated disease (both pulmonary and extra-pulmonary locations) and one patient had only extra-pulmonary disease. Fifteen patients were diagnosed with pneumonia-like illness before blastomycosis could be confirmed. One of two patients with disseminated disease (both pulmonary and extra-pulmonary locations) was diagnosed with pneumonia-like illness before blastomycosis confirmation.

Historical Case Comparison: When the 46 historical case patients were compared to the 21 outbreak cases, no significant differences in patient race, history of underlying medical conditions, hospitalization, or case fatality rates were observed (table 1). However, the outbreak case patients were significantly younger than the historic case patients with a median age (interquartile range) of 28 (18 to 47) years versus 52 (41 to 60) years, respectively $(P=0.004)$. Comparison of clinical signs and symptoms between the outbreak and historical case patients was conducted for those signs and symptoms with sufficient data available among both patient groups (table 2). The occurrence of fatigue, anorexia, cough, muscle aches, night sweats, and weight loss was similar among both groups, but fever was reported more frequently among outbreak patients. While not evaluated among the historic patients, dyspnea, headaches, and joint pain were frequently reported among outbreak patients.

Case control study: Analysis of the case-control study data identified three atypical risk factors significantly associated with occurrence of blastomycosis during this outbreak:

Table 1. Descriptive epidemiologic features among case patients with blastomycosis having onsets during the 2006 outbreak period compared with onsets during 1995-2005. All patients represented in this table resided in the 54452 zip code tabulation area in north-central Wisconsin.

\begin{tabular}{|c|c|c|c|}
\hline Descriptive Feature & $\begin{array}{c}2006 \\
\text { Outbreak (n=21) } \\
n(\%)\end{array}$ & $\begin{array}{c}1999-2005 \\
\text { Historic Cases }(n=46) \\
n(\%)\end{array}$ & $P$ value \\
\hline \multicolumn{4}{|l|}{ Sex } \\
\hline Male & $11(52)$ & $29(63)$ & $0.58^{\star}$ \\
\hline Female & $10(48)$ & $17(37)$ & $0.58^{\star}$ \\
\hline \multicolumn{4}{|l|}{ Race } \\
\hline White & $20(95)$ & $43(93)$ & $1.00 \dagger$ \\
\hline Other & $1(5)$ & $3(7)$ & $1.00 \dagger$ \\
\hline \multicolumn{4}{|l|}{ Age group (years) } \\
\hline$<15$ & $3(14)$ & $1(2)$ & $0.09 \dagger$ \\
\hline $15-24$ & $6(29)$ & $4(9)$ & $0.06 \dagger$ \\
\hline $25-44$ & $6(29)$ & $8(17)$ & $0.34 \dagger$ \\
\hline $45-64$ & $4(19)$ & $24(52)$ & $0.02^{*}$ \\
\hline$>64$ & $2(10)$ & $9(20)$ & $0.48^{\dagger}$ \\
\hline Underlying medical condition & $6(29)$ & $13(28)$ & $0.79^{\star}$ \\
\hline Hospitalized & $13(62)$ & $27(59)$ & $0.98^{\star}$ \\
\hline Died & $1(5)$ & $4(9)$ & $1.00 \dagger$ \\
\hline
\end{tabular}


Table 2. Signs and symptoms among case patients with blastomycosis having onsets during the 2006 outbreak interval compared with those having onsets during 1995-2005. All case patients resided in the 54452 zip code tabulation area in north-central Wisconsin.

\begin{tabular}{|c|c|c|c|}
\hline Signs and Symptoms & $\begin{array}{c}2006 \\
\text { Outbreak (n=21) } \\
n(\%)\end{array}$ & $\begin{array}{c}1999-2005 \\
\text { Historic Cases }(\mathrm{n}=46) \\
\mathrm{n}(\%)\end{array}$ & $P$ value \\
\hline Fatigue & $20(95)$ & $24(86)$ & $0.38^{\dagger}$ \\
\hline Fever & $16(76)$ & $13(46)$ & $0.07^{\star}$ \\
\hline Anorexia & $16(76)$ & $15(54)$ & $0.18^{\star}$ \\
\hline Cough & $16(76)$ & $24(86)$ & $0.47 \dagger$ \\
\hline Dyspnea & $15(71)$ & $\mathrm{na}^{\ddagger}$ & \\
\hline Headache & $14(67)$ & na $\ddagger$ & \\
\hline Muscle aches & $13(62)$ & $18(64)$ & $0.90^{\star}$ \\
\hline Night sweats & $13(62)$ & $18(64)$ & $0.90^{\star}$ \\
\hline Weight loss & $12(57)$ & $16(57)$ & $0.77^{\star}$ \\
\hline Joint pain & $11(52)$ & na $\ddagger$ & \\
\hline Nausea & $8(38)$ & nał & \\
\hline Wheezing & $6(29)$ & na & \\
\hline Hemoptysis & $3(14)$ & $4(14)$ & $1.00 \dagger$ \\
\hline Diarrhea & $3(14)$ & na $\ddagger$ & \\
\hline New skin rash & $2(10)$ & nał & \\
\hline
\end{tabular}

$P$ values for *Yates-corrected Mantel-Haenszel chi-square or †Fisher exact test.

‡data not available for patients with illness onset prior to 2003.

residence in an urban neighborhood within the city limits; spending $\leq 10$ hours per week outdoors; and having no history of traveling outside the county during the exposure period (table 3). While the randomly-selected control subjects were distributed in non-rural and rural population centers throughout the ZCTA, $16(76 \%)$ of 21 case patients resided within the city limits, compared with $29(45 \%)$ of 64 control subjects (MLE of $\mathrm{mOR}=3.7 ; 95 \% \mathrm{CI}=1.3-12 ; P=0.01$ ). The median center of case patient residences was in an urban neighborhood north of the Prairie River and two kilometers west of its confluence with the Wisconsin River (figure 1).

Based on the estimated incubation period and reported dates of illness onset among outbreak case-patients, exposures would likely have occurred during October 9, 2005 through February 12, 2006, had the exposures been sporadic. However, if a point source exposure was responsible, the grand median of all estimated exposure periods suggests the likely time of exposure was about December 5, 2005.

\section{Environmental Findings}

Inspections of the area by local and state health department personnel identified a municipal yard waste collection site located within 100 meters of the cluster center as the likely exposure source. Yard waste materials were deposited at the site throughout 2005 by city employees, lawn care providers, and city residents. Grass and leaves were periodically hauled from the site to a remote composting facility, but a separate, unusually large pile (approximately 50 cubic meters) of predominately white pine tree needles and small branches was allowed to accumulate. During the morning of
November 21, 2005, fourteen days prior to the grand median estimated exposure date, this material was moved using a front-end loader within the site but closer to the cluster center of case patient residences.

North-central Wisconsin experienced a moderate to severe drought with diminished precipitation levels throughout the

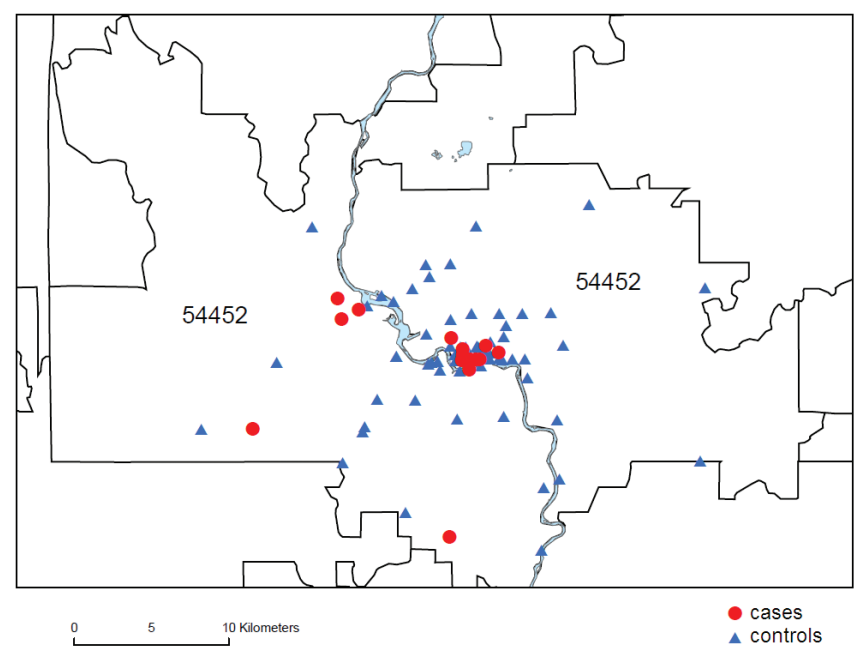

Figure 1. Map of the 54452 zip code area demonstrating the location of blastomycosis cases (red circles) and controls (blue triangles) in relationship to the Prairie River. The municipal waste site cannot be resolved at this scale but is located near the densely clustered red circles in the center of the map. 
summer of 2005, followed by a period of normal to above-normal precipitation that coincided with the estimated exposure period for the 21 outbreak case patients (figure 2). During a three day period that began one week after relocation of the pine needle pile, weather conditions were unseasonably warm (temperatures averaging $11^{\circ} \mathrm{C}$ above normal) and rainy (1.2 inches of precipitation). This was accompanied by seven days of brisk winds (range $=0-8.9 \mathrm{~m} / \mathrm{s}$, mean $=2.6 \mathrm{~m} / \mathrm{s}$ ) blowing steadily toward the cluster center of case patient residences from the suspected exposure site.

\section{Laboratory Findings}

PCR amplification, using primers in the putative promoter region of the $B$. dermatitidis BAD1 virulence gene, was positive in multiple replicates from only one of 19 environmental samples. The positive sample was collected from a pile of pine tree litter that was relocated to an off-site facility just prior to sampling. None of the environmental samples, including the PCR-positive ones, yielded $B$. dermatitidis using mouse inoculation or culture methods.

PCR-RFLP typing of 14 outbreak and 40 non-outbreak clinical isolates and the ATCC reference strain \#26199 identified four RFLP patterns; $13(93 \%, P=0.002)$ of 14 outbreak isolates were identified as RFLP-Type A (figure 3).

Among the nine case patients and 36 control subjects who consented to participate in the clinical laboratory investigation,

Table 3. Risk factors for case-patients and matched control subjects during the estimated exposure period prior to the 2006 blastomycosis outbreak in the 54452 zip code tabulation area in north-central Wisconsin.

\begin{tabular}{|c|c|c|c|c|}
\hline Risk Factor & $\begin{array}{l}\text { Case Patients } \\
\qquad \begin{array}{c}(n=21) \\
n(\%)\end{array}\end{array}$ & $\begin{array}{l}\text { Control Subjects } \\
\qquad \begin{array}{c}(n=64) \\
n(\%)\end{array}\end{array}$ & $\begin{array}{l}\text { MLE of mOR* } \\
(95 \% \mathrm{Cl})\end{array}$ & $\boldsymbol{P}$ value ${ }^{\dagger}$ \\
\hline Within city limits & $16(76)$ & $29(45)$ & $3.7(1.3-12.0)$ & 0.01 \\
\hline Urban neighborhood & $16(76)$ & $12(36)$ & $5.5(1.8-20.2)$ & 0.001 \\
\hline Wetlands on property & $5(26)$ & $15(23)$ & $1.1(0.3-3.4)$ & 0.53 \\
\hline Firewood stored indoors & $3(16)$ & $13(20)$ & $0.8(0.2-3.0)$ & 0.50 \\
\hline Dog living in household & $16(76)$ & $38(59)$ & $2.0(0.7-6.8)$ & 0.15 \\
\hline \multicolumn{5}{|l|}{ Outdoor Activities } \\
\hline Non-occupational work activities & $10(48)$ & $33(52)$ & $0.9(0.3-2.8)$ & 0.55 \\
\hline Landscaping & $0(0)$ & $3(5)$ & undefined $\ddagger$ & \\
\hline Clearing brush of cutting trees & $4(19)$ & $19(30)$ & $0.6(0.2-2.0)$ & 0.29 \\
\hline Digging or excavating & $4(19)$ & $4(6)$ & $5.3(0.9-44.0)$ & 0.07 \\
\hline Gardening & $0(0)$ & $7(11)$ & undefined $\ddagger$ & \\
\hline Collecting or transporting yard waste & $7(37)$ & $20(32)$ & $1.4(0.4-4.4)$ & 0.39 \\
\hline Exposure to rotting wood or vegetation & $8(38)$ & $30(47)$ & $0.7(0.3-2.0)$ & 0.36 \\
\hline Recreational activities & $13(62)$ & $42(66)$ & $0.9(0.3-2.6)$ & 0.51 \\
\hline Walking, jogging, or biking near waterways & $9(43)$ & $33(52)$ & $0.8(0.3-2.0)$ & 0.37 \\
\hline Along exposed riverbank or shoreline & $4(21)$ & $9(14)$ & $2.1(0.4-9.8)$ & 0.26 \\
\hline Immunosuppressive medications & $2(10)$ & $1(2)$ & $6.5(0.5-198.0)$ & 0.15 \\
\hline Cigarette smoking & $4(19)$ & $18(28)$ & $0.5(0.1-1.9)$ & 0.23 \\
\hline \multicolumn{5}{|c|}{$\begin{array}{l}{ }^{*} \mathrm{MLE} \text { of mOR=Maximum Likelihood Estimate of the Matched Odds Ratio; } 95 \% \mathrm{Cl}=\mathrm{Exact} 95 \% \text { mid- } P \text { Confidence Interval } \\
+P \text { values for Yates-corrected Mantel-Haenszel chi-square }\end{array}$} \\
\hline
\end{tabular}




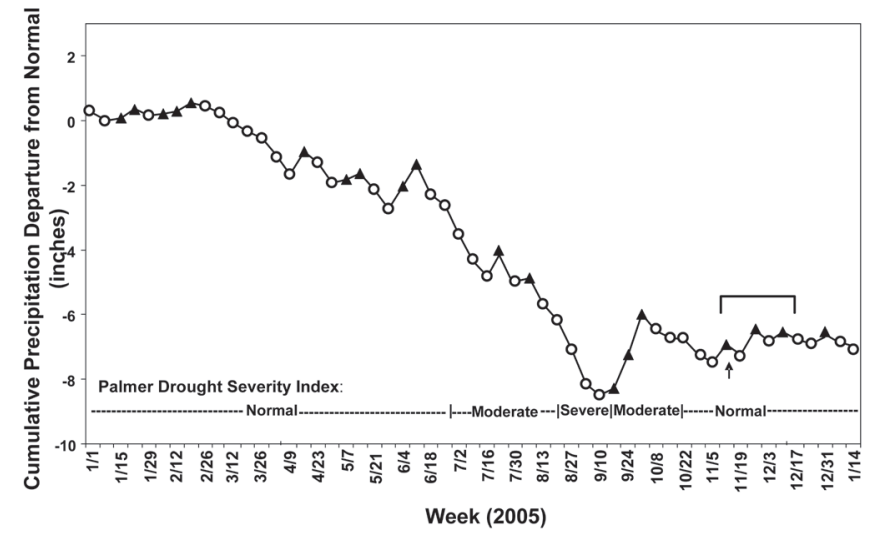

Figure 2. Cumulative weekly precipitation departures from normal (in inches) during 2005, showing weeks with below $\left(\hat{Q}_{Q}\right)$ and above ( ) normal precipitation. A moderate to severe drought resulted from precipitation levels 8.3 inches below normal during the period from March through mid-September 2005. This period of diminished precipitation was followed by a period of above-normal to normal precipitation during which time the pine needle pile was moved on November 21, 2005 ( $\boldsymbol{t}$ ) and subsequently followed by the estimated exposure period for the 21 blastomycosis outbreak case patients ( $\longmapsto$ ).

all urine specimens tested negative for Blastomyces antigen. Five $(56 \%)$ of nine case-patient serum specimens were positive for antibody by EIA, compared with one (3\%) of 36 control subject serum specimens $(P<0.001)$, one $(17 \%)$ of six city employee specimens $(P=0.29)$, one $(33 \%)$ of three specimens from household members of case patients $(P=1.00)$, and none of six specimens from daycare workers or clients $(P=0.04)$. The control subject who tested positive was excluded from the case-control data analysis.

\section{Discussion}

This outbreak of blastomycosis is the second largest ever reported and the largest in a non-rural setting. It occurred in a small urban area in north-central Wisconsin with a population of approximately 10,000. The community lies at the confluence of the Wisconsin and Prairie Rivers and is surrounded by an ecological landscape characterized by agricultural areas intermixed with forests containing northern hardwoods, white pine, red pine, and yellow birch.

Prior investigations of presumed common source outbreaks have linked acquisition of infection with exposure to construction sites, ${ }^{20-22}$ living near a peanut farm, ${ }^{23}$ raccoon hunting in swampy woods ${ }^{24}$ canoeing and fishing on Wisconsin rivers, ${ }^{25,26}$ digging in an underground fort and animal burrow, ${ }^{26}$ and visiting a beaver dam and lodge. ${ }^{8}$ In the only other recorded non-rural outbreak, case patients were presumably infected during exposure to heavy airborne dust while residing or driving near suburban Chicago road construction excavation sites. ${ }^{21}$ Airborne dust was also implicated in a 1988 outbreak 270 meters to 400 meters downwind from a hotel excavation site in northern Wisconsin. ${ }^{27}$
Blastomycosis most commonly occurs among middle-aged men, probably due to sporadic exposure to $B$. dermatitidis in ecologic niches during occupational and recreational activities involving close contact with soil or vegetation, primarily near waterways. ${ }^{3}$ In this investigation, 21 cases of blastomycosis within a 9-week interval, the younger age of case patients and the lack of statistically significant associations between illness and any typically recognized blastomycosis risk factors suggest a point source outbreak rather than sporadic exposures. Notably, case patients were more likely to spend less time $(<10$ hours $)$ outdoors than controls $(P=0.04)$. Most case patients likely were exposed merely by their presence in a specific, limited geographic area within the city.

The most likely exposure site, implicated by epidemiologic investigation and inspections, was a yard waste collection site located near a residential neighborhood. The composting process depends on degradation of organic wastes by microbial activity. Whenever organic waste materials are manipulated, such as during shredding, turning, and screening processes, these microorganisms can be aerosolized. ${ }^{28}$ Large increases in bioaerosol levels occur near actively agitated compost piles compared to quiescent piles and can impact neighboring residential areas. ${ }^{29}$ Dispersal of $B$. dermatitidis spores liberated during the composting process has not been previously documented. However, Aspergillus fumigatus, an allergenic opportunistic fungal pathogen with spores similar in size to $B$. dermatitidis, is a well known constituent of compost bioaerosols. ${ }^{30,31}$ When bioaerosols are produced through mechanical agitation of compost piles, studies demonstrate the numbers of $A$. fumigatus spores decline to background levels within 200 meters from the source, although the distance may be greater under certain atmospheric conditions. ${ }^{28}$ These studies with A. fumigatus and the two previously reported blastomycosis outbreaks associated with airborne dust exposure suggest a potential hazard may exist within and near yard material collection, especially where pine tree litter is present, or composting facilities in areas endemic for blastomycosis. In this outbreak, the use of a front-end loader to move a pile of pine tree litter appears to have inadvertently contributed to the dispersal of infectious conidia.

Conditions important for growth of $B$. dermatitidis and formation, release, and dispersal of its conidia include decayed and rotting vegetation or debris with high organic content and low $\mathrm{pH}^{8,32}$ periods of decreased precipitation followed by introduction of moisture, and warming of the soil. ${ }^{4}$ Recent rainfall was reported prior to the environmental recovery of $B$. dermatitidis following several documented point source outbreaks. ${ }^{15,25,33-35}$ All of these environmental conditions existed prior to and during the estimated exposure period of this outbreak.

PCR-RFLP patterns of clinical $B$. dermatitidis isolates from this ZCTA prior to and during 2006 were nearly equally distributed between two distinct genetic types. Genetic typing of available outbreak-associated isolates revealed that all but 


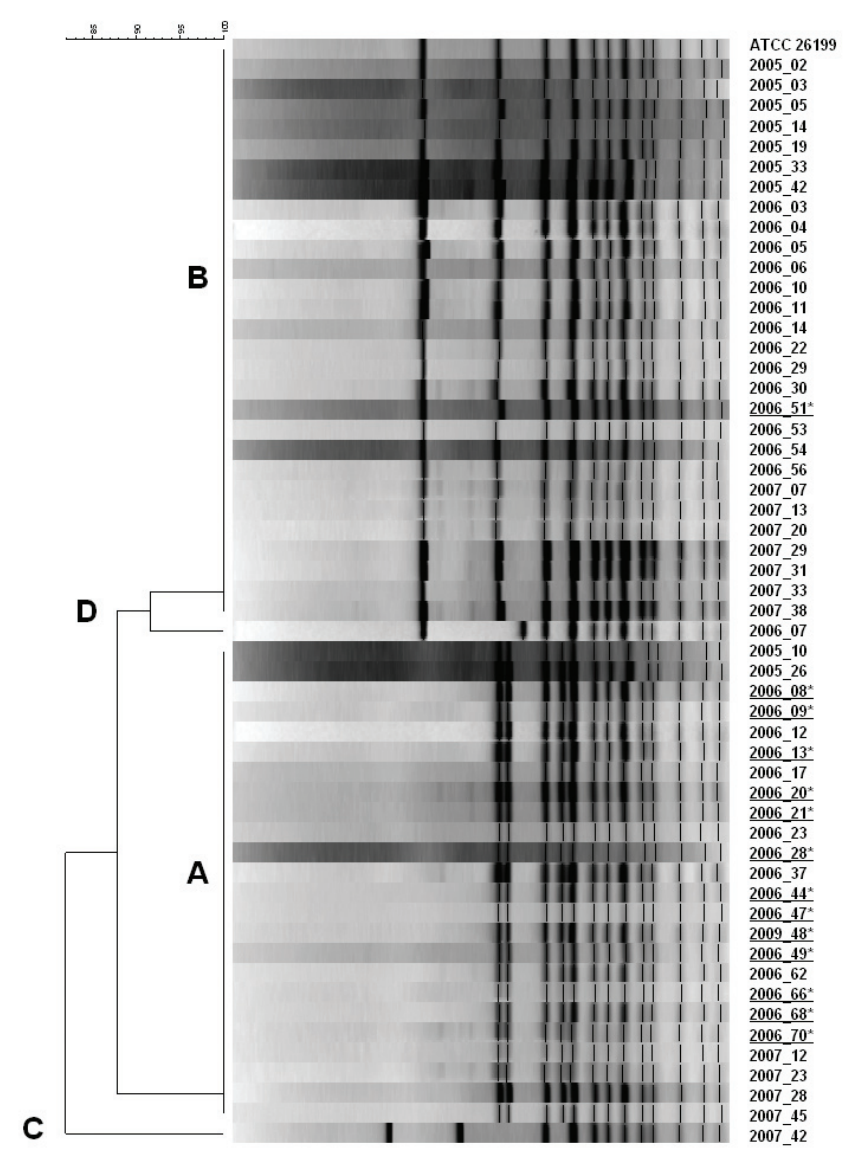

Figure 3. Outbreak and non-outbreak associated isolates of Blastomyces dermatitidis are shown grouped into 4 genetic types. Isolates obtained from case patients during the 2006 outbreak of blastomycosis in the 54452 zip code tabulation area in north-central Wisconsin are underlined; 13 of these 14 epidemiologically-linked isolates clustered in RFLP Group A.

one was genetically similar using PCR-RFLP, providing additional evidence of a single-source exposure. Upon further investigation, it was discovered that the single case with an alternate genetic type may have resulted from a different source, as more than one potential exposure was reported on this individual's Wisconsin Division of Public Health case report form.

Our attempts to cultivate $B$. dermatitidis from suspected environmental sites by in vitro and in vivo methods were unsuccessful. Environmental conditions that support $B$. dermatitidis growth in geographically-restricted microfoci are apparently short-lived. ${ }^{34}$ When sporadic cases or outbreaks of blastomycosis are identified, environmental conditions may no longer exist to support growth of $B$. dermatitidis making environmental isolation difficult. Despite thousands of attempts, successful isolation of the mold from the environment has only occurred 21 times. Repeated isolation from sites, where previously the mold was present, has been unsuccessful. In this investigation, about four months elapsed between the likely exposure period and collection of samples; furthermore, the probable exposure source was again disturbed and relocated before samples could be obtained. Therefore, the inability to cultivate $B$. dermatitidis from the environmental samples is not evidence that $B$. dermatitidis was not present at the time and location of the presumed exposure.

We detected nucleic acid evidence of $B$. dermatitidis in one environmental sample. While the detection of $B$. dermatitidis nucleic acid using PCR is promising for investigating the ecologic and epidemiologic features of $B$. dermatitidis, further study of its accuracy is needed. Recently, it has been discovered that some strains of $B$. dermatitidis contain large insertions in the BAD1 gene putative promoter region, from which the Blasto I and Blasto II primers were designed. ${ }^{35}$ Because these strains of $B$. dermatitidis are highly represented ( $\sim 50 \%$ of isolates) in Wisconsin, the utility of the assay for environmental detection could be affected. PCR parameters using these primers have not been optimized for samples when larger amplicons are expected. This is of special concern for environmental samples because of the wide range of inhibitory factors inherent to soil samples that may complicate nucleic acid extraction and amplification. ${ }^{36}$ Notably, 13 of the 14 outbreak case patient isolates described here contain insertions in the Blasto I and Blasto II amplification region. The remaining isolate (2006-51) does not contain the insertions and is also genetically different by PCR-RFLP. The PCR positive environmental sample did not contain the insertions and showed the expected product size of $363 \mathrm{bp}$. Although the PCR positive environmental sample is not the same genetic type suspected of causing the outbreak, we have evidence to suggest that both genetic types are robustly represented in clinical isolates from this region of Wisconsin and, therefore, possibly occur together in the environment. We cannot definitively link the same genetic type of $B$. dermatitidis to both the clinical outbreak isolates and the pine tree litter pile; however, detection of genetic material suggests the pile's suitability to support growth of B. dermatitidis.

Although the $B$. dermatitidis urine antigen assay appears to be useful in providing a rapid diagnosis of pulmonary or disseminated blastomycosis, ${ }^{18}$ it was not helpful in this investigation. However, the specimens were obtained approximately six months after the estimated exposure period. Therefore, our investigation was not able to address the sensitivity of antigen detection for diagnosis of acute blastomycosis.

The accuracy of serologic testing is inadequate for diagnosis of blastomycosis. ${ }^{37}$ EIA methods are more sensitive than immunodiffusion and complement fixation tests, but less specific, ${ }^{3,8,38,39}$ and the sensitivity of EIA decreases with increasing time after infection. ${ }^{40}$ In our investigation, only half of the available specimens obtained from case patients were EIA positive, probably due to the 6-month interval between infection and testing. Although one of six city employees was positive using the EIA method, no information 
was available regarding any contact the individual may have had with the pine tree litter pile or his address of residence. Because only one control subject recruited from this endemic area tested positive (and was excluded from data analysis), our classification of control subjects as uninfected with $B$. dermatitidis was presumed valid.

\section{Conclusion}

In this outbreak, the collection, storage, and mechanical manipulation of a large pile of pine needle yard waste during favorable meteorological conditions may have inadvertently facilitated growth, conidia formation, and dispersal of $B$. dermatitidis in close proximity to a residential area. We recommend that in areas where blastomycosis is endemic: (1) community yard waste management activities should be located away from residential properties; (2) employees engaged in mechanical agitation of decayed and rotting vegetation and organic debris should consider the use of appropriate respiratory protective equipment; (3) residents, especially those with impaired immune systems, should be aware of the risks associated with soil-disturbing activities (eg, gardening or landscaping) and consider the use of HEPA-filter or dust masks when participating in such activities; (4) persons living in endemic regions, particularly the elderly or immune compromised, should be aware of signs and symptoms of blastomycosis and immediately contact their health care providers if they have an illness consistent with blastomycosis; and (5) clinicians should suspect blastomycosis in anyone presenting with moderate or moderately severe pneumonia-like illness who does not have a definitive diagnosis by standard testing and has not had a timely response to conventional management.

\section{Acknowledgements}

We thank Steve Foley, PhD and Po-Huang Chyou, $\mathrm{PhD}$ for assistance in preparation of this manuscript.

\section{References}

1. Bradsher RW, Chapman SW, Pappas PG. Blastomycosis. Infect Dis Clin North Am 2003;17:21-40.

2. Sarosi GA, Davies SF. Blastomycosis. Am Rev Respir Dis 1979;120:911-938.

3. Klein BS, Vergeront JM, Davis JP. Epidemiologic aspects of blastomycosis, the enigmatic systemic mycosis. Semin Respir Infect 1986;1:29-39.

4. McDonough ES, Wisniewski TR, Penn LA, Chan DM, McNamara WJ. Preliminary studies on conidial liberation of Blastomyces dermatitidis and Histoplasma capsulatum. Sabouraudia 1976;14:199-204.

5. Baumgardner DJ, Knavel EM, Steber D, Swain GR. Geographic distribution of human blastomycosis cases in Milwaukee, Wisconsin, USA: association of urban watersheds. Mycopathologia 2006;161:275-282.

6. Reed KD, Meece JK, Archer JR, Peterson AT. Ecologic niche modeling of Blastomyces dermatitidis in Wisconsin. PLoS ONE 2008;3:e2034.

7. Waksberg J. Sampling methods for random digit dialing. J Am Stat Assoc 1978;73:40-46.
8. Klein BS, Vergeront JM, Weeks RJ, Kumar UN, Mathai G, Varkey B, Kaufman L, Bradsher RW, Stoebig JF, Davis JP. Isolation of Blastomyces dermatitidis in soil associated with a large outbreak of blastomycosis in Wisconsin. N Engl J Med 1986;314:529-534.

9. Dean AG, Arner TG, Sunki GG, Friedman R, Lantinga M, Sangam S, Zubieta JC, Sullivan KM, Brendel KA, Gao Z, Fontaine N, Shu M, Fuller G, Smith DC, Nitschke DA, Fagan RF. Epi Info ${ }^{\mathrm{TM}}$, a database and statistics program for public health professionals. V 3.5. Centers for Disease Control and Prevention, Atlanta, Georgia, USA, 2008.

10. Levine N. CrimeStat: a spatial statistics program for the analysis of crime incident locations. V 3.0. Ned Levine \& Associates, Houston, TX, and the National Institute of Justice, Washington, DC. 2004.

11. National Climatic Data Center. Jan 1, 2005-Feb 12, 2006. Online Climate Data Directory. Surface data for Merrill, WI, Available at: http://cdo.ncdc.noaa.gov/pls/plclimprod/ cdomain.abbrev2id/. Accessed 5 Apr 2006.

12. Bialek R, Cirera AC, Herrmann T, Aepinus C, Shearn-Bochsler VI, Legendre AM. Nested PCR assays for detection of Blastomyces dermatitidis DNA in paraffin-embedded canine tissue. J Clin Microbiol 2003;41:205-208.

13. Burgess JW, Schwan WR, Volk TJ. PCR-based detection of DNA from the human pathogen Blastomyces dermatitidis from natural soil samples. Med Mycol 2006;44:741-748.

14. Baumgardner DJ, Paretsky DP. The in vitro isolation of Blastomyces dermatitidis from a woodpile in north central Wisconsin, USA. Med Mycol 1999;37:163-168.

15. Denton JF, DiSalvo AF. Isolation of Blastomyces dermatitidis from natural sites in Augusta, Georgia. Am J Trop Med 1964;13:716-722.

16. McCullough MJ, DiSalvo AF, Clemons KV, Park P, Stevens DA. Molecular epidemiology of Blastomyces dermatitidis. Clin Infect Dis 2000;30:328-335.

17. Nei M. Molecular Evolutionary Genetics. New York, NY: Columbia University Press; 1987.

18. Durkin M, Witt J, LeMonte A, Wheat B, Connolly P. Antigen assay with the potential to aid in diagnosis of blastomycosis. J Clin Microbiol 2004;42:4873-4875.

19. Spector D, Legendre AM, Wheat J, Bemis D, Rohrbach B, Taboada J, Durkin M. Antigen and antibody testing for the diagnosis of blastomycosis in dogs. J Vet Intern Med 2008;22:839-843.

20. Frye MD, Seifer FD. An outbreak of blastomycosis in eastern Tennessee. Mycopathologia 1991;116:15-21.

21. Kitchen MS, Reiber CD, Eastin GB. An urban epidemic of North American blastomycosis. Am Rev Respir Dis 1977;115:1063-1066.

22. Tosh FE, Hammerman KJ, Weeks RJ, Sarosi GA. A common source epidemic of North American blastomycosis. Am Rev Respir Dis 1974;109:525-529.

23. Centers for Disease Control and Prevention. Blastomycosis North Carolina. MMWR 1976;25:205-206.

24. Armstrong CW, Jenkins SR, Kaufman L, Kerkering TM, Rouse BS, Miller GB Jr. Common source outbreak of blastomycosis in hunters and their dogs. J Infect Dis 1987;155:568-570.

25. Cockerill FR 3rd, Roberts GD, Rosenblatt JE, Utz JP, Utz DC. Epidemic of pulmonary blastomycosis (Namekagon fever) in Wisconsin canoeists. Chest 1984;86:688-692.

26. Klein BS, Vergeront JM, DiSalvo AF, Kaufman L, Davis JP. Two outbreaks of blastomycosis along rivers in Wisconsin. Isolation of Blastomyces dermatitidis from riverbank soil and evidence of its transmission along waterways. Am Rev Respir Dis 1987;136:1333-1338.

27. Baumgardner DJ, Burdick JS. An outbreak of human and canine blastomycosis. Rev Infect Dis 1991;13:898-905. 
28. Millner PD, Olenchock SA, Epstein E, Rylander R, Haines J, Walker J, Ooi BL, Horne E, Maritato M. Bioaerosols associated with composting facilities. Compost Sci Util 1994;2:6-57.

29. Recer GM, Browne ML, Horn EG, Hill KM, Boehler WF. Ambient air levels of Aspergillus fumigatus and thermophilic actinomycetes in a residential neighborhood near a yardwaste composting facility. Aerobiologia 2001;17:99-108.

30. Ault SK, Schott M. Aspergillus, aspergillosis, and composting operations in California. California Integrated Waste Management Board Technical Bulletin No. 1: 1994. Available at: http://www.ciwmb.ca.gov/LEAAdvisory/06/06attch.doc. Accessed July 6, 2007.

31. DiSalvo AF. The epidemiology of blastomycosis. In: Al-Doory Y,. DiSalvo A, eds. Blastomycosis. New York, NY: Plenum Medical Book Company; 1992. 75-104.

32. Sarosi GA, Serstock DS. Isolation of Blastomyces dermatitidis from pigeon manure. Am Rev Respir Dis 1976;114:11791183.

33. De Groote MA, Bjerke R, Smith H, Rhodes III LV. Expanding epidemiology of blastomycosis: clinical features and investigation of 2 cases in Colorado. Clin Infect Dis 2000;30:582-584.

34. Denton JF, DiSalvo AF. Additional isolations of Blastomyces dermatitidis from natural sites. Am J Trop Med Hyg 1979;28:697-700.

35. Meece JK, Anderson JL, Klein BS, Sullivan TD, Foley SL, Baumgardner DJ, Brummitt CF, Reed KD. Genetic diversity in Blastomyces dermatitidis: implications for PCR detection in clinical and environmental samples. Med Mycol 2010;48:285-90.

36. Wilson IG. Inhibition and facilitation of nucleic acid amplification. Appl Environ Microbiol 1997;63:3741-3751.

37. Bradsher RW. Therapy of blastomycosis. Semin Respir Infect 1997;12:263-267.

38. Klein BS, Vergeront JM, Kaufman L, Bradsher RW, Kumar UN, Mathai G, Varkey B, Davis JP. Serological tests for blastomycosis: assessments during a large point-source outbreak in Wisconsin. J Infect Dis 1987;155:262-268.

39. Sekhon AS, Kaufman L, Kobayashi GS, Moledina NH, Jalbert $M$. The value of the Premier enzyme immunoassay for diagnosing Blastomyces dermatitidis infections. J. Med Vet Mycol 1995;33:123-125.

40. Bradsher RW, Pappas PG. Detection of specific antibodies in human blastomycosis by enzyme immunoassay. South Med J 1995;88:1256-1259.

\section{Author Affiliations}

John R. Pfister, MS*; John R. Archer, MSt;

Shelly Hersil, BS, CHESł; Tammi Boers, RSt;

Kurt D. Reed, MD, MGIS\$; Jennifer K. Meece, PhD"/, Jennifer L. Anderson, BS"/, Joshua W. Burgess, PhD\#; Thomas D. Sullivan, PhD ${ }^{* *}$; Bruce S. Klein, MD ${ }^{* *}$; L. Joseph Wheat, MD ${ }^{\dagger+}$; and Jeffrey P. Davis, MD广

*Wisconsin State Laboratory of Hygiene, Madison, WI, USA † Bureau of Communicable Disease and Emergency Response, Wisconsin Division of Public Health, Madison, WI, USA

$\ddagger$ Lincoln County Health Department, Merrill, WI, USA

$\S$ Northwestern University Feinberg School of Medicine,

Chicago, IL, USA

"Marshfield Clinic Research Foundation,

Marshfield, WI, USA

\#University of North Carolina at Chapel Hill,

Chapel Hill, NC, USA

** School of Medicine and Public Health, University of Wisconsin, Madison, WI, USA

†MiraVista Diagnostics, Indianapolis, IN, USA 